\title{
E- learning for smart-universities: pandemic challenges and opportunities in Morocco
}

\author{
Mohamed Anigri \\ Ibn Zohr University, LVSD lab., Agadir, Morocco \\ mohamed.anigri@edu.uiz.ac.ma
}

\begin{abstract}
Both ICT and internet have become a vital part of citizens' daily lives. In fact, many aspects of cities, including culture, economy, education have become closely linked to ICT. Accordingly, the concept of the smart city has emerged to attract the interest of governments, companies, educational institutions and Universities [1]. In Morocco, most universities or higher education institutions have always been interested in keeping up with the fast-paced world of technology and integrate ICT in mainstream education. However, most attempts to initiate smart universities is always faced with a series of challenges and constraints. Most of which are related to lack of infrastructure, students' and professors' lack of technological readiness, and socio-economic inequality among students. Most recently, due to COVID-19, universities are forced to resort to emergency remote learning and scramble different options of e-learning as a dire need to tackle the current educational crisis which creates a certain chaos due to lack of readiness to an advanced technological application. This paper is an attempt to discuss the challenges posed and opportunities offered using e- learning to deal with the new normal (Covid-19) in different educational levels in general and higher education in particular. Significantly, this paper reviews most of that has been said about online learning, describes some of the conducted empirical studies, and calls for implementing e-learning as an innovative teaching strategy for smart universities.
\end{abstract}

Keywords: Smart cities/universities, e-learning, covid-19, challenges, opportunities, higher education

\section{Introduction}

In the aftermath of most calamities, be they natural or human, knowledge delivery becomes a challenging task. In March 2020, the general director of WHO declared Covid-19 as a pandemic after assessing its spread and severity across the globe. Following this declaration comes the precautionary measures to deal with the new situation. Amongst these measures is a strict social distancing to curb the spread of the virus which necessitates an immediate global physical closure of schools in order to protect students, faculty, academic staff, communities, and the nation as a whole. According to the UNESCO, at the end of April 2020, most educational institutions shut down in almost all countries affecting approximately $74 \%$ of learners on the planet [2].

Indisputably, Covid 19 pandemic has an unprecedented impact in that it hampers the provision of face-to-face courses on a global scale. Indeed, this pandemic has disrupted educational systems worldwide and the belief in face-to-face learning mode starts losing its relevance [3]. Many universities, that used to believe in the power of face-to-face, scrambled to provide academic continuity through "emergency remote plan" [4]. Even before pandemic there was already a widespread acknowledgement that e-learning has challenged the traditional face-to-face higher educational model [5]. During pandemic, the traditional mode is seriously pummelled as online learning has become a necessity in higher education [5].

This paper is an attempt to discuss the impact of the current situation on both teachers and students -especially that there is no infrastructure, no prior knowledge or training to adopt 
online learning mode. It also highlights the offered opportunities dealing with the new normal; thus, the e-learning modality is suggested, henceforth, as the panacea for any educational crisis. Most importantly, this paper aims to propagate, among stakeholders, that e-learning has to be adopted as a teaching strategy for future Moroccan smart universities.

\section{E- learning}

Against the backdrop of this pandemic, various policy initiatives are launched by governments and educational institutions to cater for students' learning. Ensuring learning continuity during school closures becomes a priority to turn to ICT, which requires that teachers move to emergency distance teaching modalities, namely electronic or online learning.

E-learning or online learning has been described as an attempt to associate learning with the use of new technologies, namely internet, intranet [6]. In other words, it represents a twosided relationship between student and teacher which aims at helping students to learn through the use of the Internet [7]. Online learning has been divided into three main categories, which can be summarized and grouped into the following table [6].

Table 1. The Three Online Modes

\begin{tabular}{|l|l|}
\hline Online Learning Category & \multicolumn{1}{c|}{ Description } \\
\hline Web-supplemented & $\begin{array}{l}\text { Face-to-face teaching mode is supplemented by web } \\
\text { content, } \\
\text { Students can have access to the course descriptions, } \\
\text { examination details or reading lists on units of study. }\end{array}$ \\
\hline Web-dependent & $\begin{array}{l}\text { Face-to face is still part of the learning environment. } \\
\text { Students' online participation is paramount. }\end{array}$ \\
\hline Fully online & $\begin{array}{l}\text { Do not have any face-to-face component, } \\
\text { All aspects of learning are integrated and delivered } \\
\text { online. }\end{array}$ \\
\hline
\end{tabular}

Most low-income countries that were earlier reluctant to change their traditional pedagogical approach are forced to shift to fully online mode of teaching overnight. However, the application of this mode is challenged by the lack of infrastructure, knowledge, and training. Therefore, As shown in Figure 1, low income countries resort to traditional distance learning modalities while high income countries move to more online- based modalities [8]. In statistical terms, online learning in high income countries covers about 8085 per cent, while this drops to 50 per cent in low income countries [8]. 

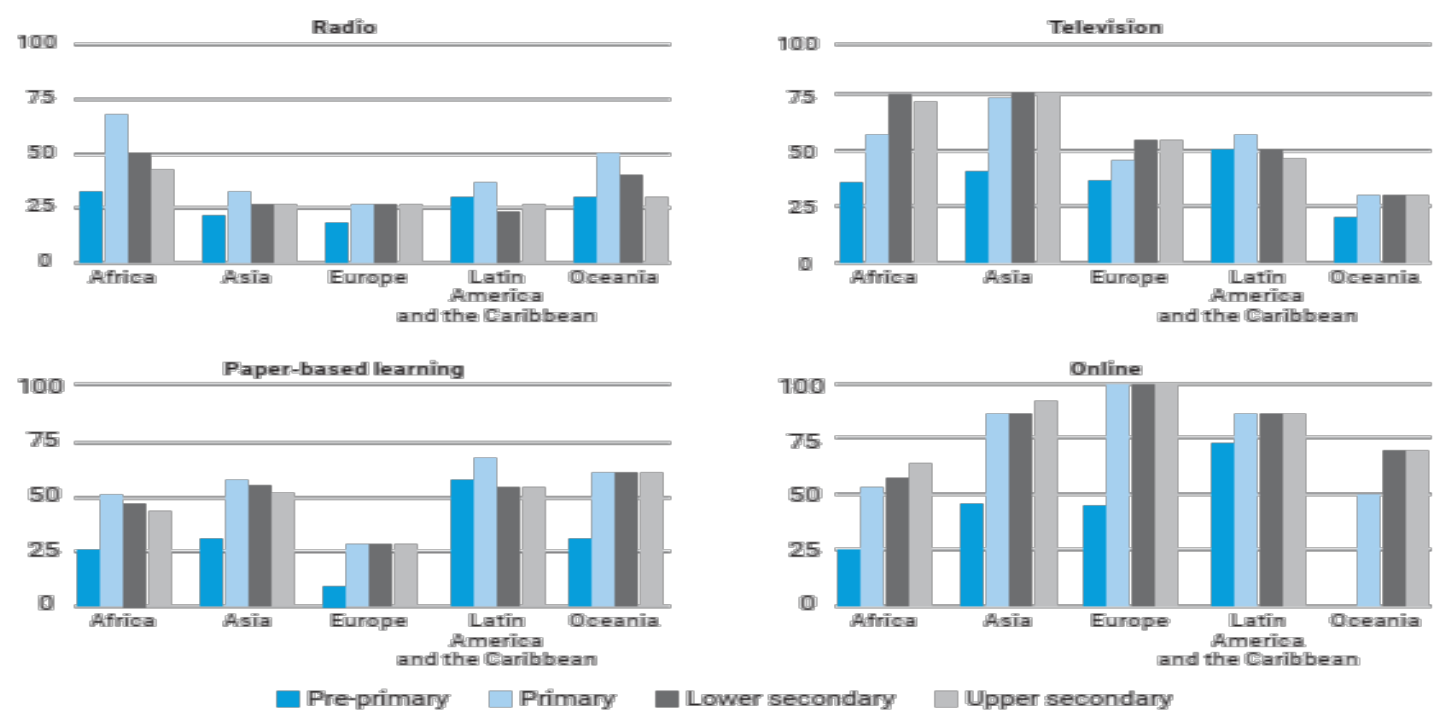

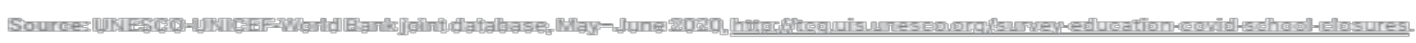

Fig.1. Teaching modalities across countries during school closure [8]. P. 13

\section{Weaknesses and Challenges}

Apparently, the global spread of Covid-19 poses a challenge to the higher education landscape at an unprecedented magnitude. Universities cancelled their onsite classes and shifted their pedagogical processes to online media. Needless to say, moving online without any previous training carries with it many challenges and dilemmas [9]. The situation does not hold for universities that are used to such innovative modalities, but rather to those encountering such forms of teaching for the first time [10]. Table 2 is meant to summarize the main issues related to online teaching, some of which can be discussed in detail in the subsequent paragraphs.

Table 2. Major issues related to online teaching [11]

\begin{tabular}{|l|l|}
\hline \multicolumn{1}{|c|}{ Issues } & \multicolumn{1}{|c|}{ Description } \\
\hline Learners' accessibility issues & $\begin{array}{l}\text { The required technology is unavailable. } \\
\text { Some phones and laptops are not } \\
\text { compatible. } \\
\text { Issues with correct browsers for learning. } \\
\text { Lack of adequate internet access. } \\
\text { The cost of the internet is too high. } \\
\text { The online learning environment is not } \\
\text { motivating. }\end{array}$ \\
\hline Lecturer issue & $\begin{array}{l}\text { Not all teachers have the required } \\
\text { technology. } \\
\text { Lecturers are not trained to teach online }\end{array}$ \\
\hline Social issues & $\begin{array}{l}\text { Lack of communication among learners } \\
\text { Lack of group discussions during } \\
\text { assignments } \\
\text { Online learning is too indirect and makes } \\
\text { learners isolated. }\end{array}$ \\
\hline
\end{tabular}




\section{Challenges for university teachers}

From the onset of the pandemic, it was imperative for teachers to implement distance learning modalities, without sufficient guidance, training or resources. Most university teachers still do not adopt technology because they do not accept it or they face difficulty using it. Even in contexts with adequate infrastructure and connectivity, many educators lack the most basic ICT skills [8]. However, it is clearly stated that traditional classroom methods are no longer effective in that they cannot fully engage 21st century students [12]. Teachers with a long experience can be good at traditional classroom, can perform even better using technology [12]. The resistance can probably be due to the difficulty or exposure to advanced technological tools at their first stage of learning. That is why, they need to start with easyto-use software and hardware in their teaching [12].

However, teachers need to know that online teaching is not simply sharing learning materials online. There must be a certain level of organization concerning content as well as the new learning method so that learners are not left stranded facing the learning challenges. Therefore, appropriate knowledge and skills as well as rudimentary ICT equipment must be provided for both teachers as well as students [10].

Following that, teachers need to be motivated to use technology-enhanced learning not only to attain their pedagogic goals but also to become digital practitioners [13]. To respond to the needs of the 21 st century, professors need to be engaged in professional development programs [12]. Therefore, it is highly recommended to invest in teachers' professional development programs and expose them to a myriad of chances to incorporate 21 st century EdTech learning and teaching skills. At this level, an implementation of online learning is imperative not only for professors but also for college leaders and the policy makers governing them [5].

\section{Students' learning challenges and weaknesses}

Most universities remain closed dealing with the new normal. This physical closure of universities and the adoption of distance education affect students in many ways. In Most low-income countries like Morocco, one can state that students neither have the motivation nor the infrastructure to go online.

In many studies, loss of one's daily habits as well as reduced social and physical contact with others (including the social-distancing measures) trigger negative emotions like demotivation, frustration, boredom, anxiety, confusion, anger etc. [10]. The online teaching mode commonly requires greater self-discipline and motivation to keep up with online lessons. As teachers are unfamiliar with the new mode of delivery, they overload their students with study materials and assignments [10]. So, students become less motivated as the load of work is doubled compared to how it was before the onsite classes were cancelled. Therefore, they spend less time learning, which can lead to learning loss [14].

The most serious issue is the socio-economic learning inequality. It has been stated that low income countries are less exposed to learning using digital technologies. The provision of equipment was a big challenge for institutions, faculty, and learners [15]. In fact, most students rely on the computer and free internet offered at the level of university [15]. So, the provision of necessary equipment is crucial to ensure digital equity among learner from different socio-economic backgrounds. 


\section{Opportunities}

Regardless of the challenges, the online teaching mode has offered many opportunities that can make the teaching-learning process more innovative, more student-centered, and even more flexible. In other words, this crisis has unveiled the potential of online learning and offers opportunities to look at the fruitful side of e-learning technologies.

In this respect, exposure to basic online technological tools has offered a great deal of flexibility in terms of time and location. For fully online courses and degrees, a variety of powerful new technological tools have emerged. The basic platforms in the form of Massive Open Online Courses (MOOC), e-books, e-notes, recordings, videos, and the like are of paramount importance in such hard times [16]. The basic platforms used in most Moroccan universities are: Microsoft TEAMS, live ZOOM classes, Moodle, often Facebook lives, and the platforms offered or available on the university website. Some teachers resort to basic Google products like Gmail, G-Drive, Google classroom, Google Hangouts. Just the fact of being exposed to basic technological tools and how to operate them, has led participants to rethink the status of the face-to-face teaching mode, which can become a central component of higher education [3]

The new normal has led to the development of innovative pedagogical approaches. There seems to be a radical change in almost all aspects of education, including teaching, learning, evaluation, and assessment, certification, degrees. This will encourage professors to be more active and shift their interests towards activating student agency. In this respect, the variety of e-learning opportunities will certainly enhance learning quality among students and help learners hone their high-order skills: problem-solving, critical thinking abilities and adaptability [17].

Moreover, digital education offers important advantages in the activation of student agency in that students become more responsible for their learning. That is to say, they have the possibility to take control over their learning as to what they want to learn, what they like, and what kind of support they need. This way, university students will be able to personalize their learning and become more independent. Flexibility is a central aspect in that students will have the chance to schedule or plan their time for completion of given online courses. Put differently, online educational platforms enable students to learn at their own pace, going back, re-reading, skipping, or even accelerating dealing with the target input. [14].

Furthermore, it is said that online mode of learning is easily accessible and can help students check the learning materials anytime and anywhere. Most importantly, it can even reach students in rural areas. This way, it can be considered to be a relatively cheaper mode in that students in rural areas will reduce the cost of transportation, accommodation, and the overall cost of institution-based learning [17]. Therefore, the socio-economic inequalities can be reduced if students were offered rudimentary equipment to reap the benefits of time and location flexibility associated with online learning.

\section{Conclusion}

All in all, we have to admit that disasters will continue to occur and that technology is the only smart solution to overcome any educational crisis caused by any of the calamities. Therefore, it is high time that Moroccan universities and higher education institutions go smart and try to catch up with the fast-paced world of technology. So, for stakeholders to harness the potential of e-learning as an innovative teaching strategy, there is a dire need to weigh the pros and the cons through well-planned procedures and amendments in order to shift from exclusively counting on traditional teaching modes to being open to smart teaching modalities that should offer a myriad of learning opportunities. 


\section{References}

1. Yin, Chuantao et al. A Literature Survey on Smart Cities. http://www.researchgate.net, (2015).

2. Di Pierto, G., et al.. The likely impact of COVID-19 on education: Reflections based on the existing literature and recent international datasets. JRC Technical Report. https://publications.jrc.ec.europa.eu, (2020).

3. Lalani, Farah and Li, C. The COVID-19 pandemic has changed education ever. This is how. -http://www.weforum.org. The World Economic Forum.

4. DeVaney, James et al. Higher ed Needs Long-Term Plan for Virtual Learning. www.hbr.org, May 2020.

5. Gallagher, Sean \& Palmer, James. The Pandemic Pushed Universities Online. The Change Was Long Overdue. www.hbr.org, (2020).

6. Mohd Fouad \& Mohd Sallleh. E-learning Issues in Malaysian Higher Education. PENERBIT. UNIVISION PRESS. Malaysia, (2008)

7. Barr, B.A., et al. Higher Education: The Online Teaching and Learning Experience. https://files.eric.ed.gov, (2013).

8. The United Nations. Policy Brief: Education during COVID-19 and beyond. http://www.un.org. PP 1.12.13, (2020)

9. Wahab, A.. Educational Challenges Amidst Covid-19 Pandemic. http://www.researchgate.net University of Fiji, (2020).

10. Aristovnik, Aleksander et. al. Impacts of the COVID-19 Pandemic on life of Higher Education Students: A Global Perspective. http://www.mbpi.com/journal/sustainability. (2020).

11. Aboagye, Emmanuel. COVID-19 and E-learning the challenges of Students in Tertiary Institutions in Ghana. http://researchgate.net. Social Education Research. June 2020.

12. Bhatt, Dhara \& Maniar, Avani. Information and Communication Technology in Higher Education-Help and Challenge. Vol 5, issue 6, (2016)

13. Bennett, S. Distance Learning in Law. Seton Hall Legislative Journal [Vol. 38:1https://scholarship.shu.edu, (2014)

14. Biagi, F., et al.. The likely impact of Covid-19 on Education: Reflections based on the existing literature and recent international datasets. https:// ec.europa.eu/jrc. Luxembourg Publication Office of the European union, (2020)

15. Adydoyin, Olasile B. Covid -19 Pandemic and online learning: the challenges and Opportunities. http:// www. researchgate.net. Near East University,(2020).

16. Huang, R. H., et al. Handbook on facilitating flexible Learning during education disruption: The Chinese experience in maintaining undisrupted learning in Covid-19 outbreak. Smart learning Institute of Beijing Normal University, (2020).

17. Dhawan, S. Online Learning: A Panacea in the Time of COVID-19 Crisis. http://Journals.sagepub.com. Journal of Educational Technology, (2020). 